\title{
The epigenome and the mitochondrion: bioenergetics and the environment
}

\author{
Douglas C. Wallace ${ }^{1}$ \\ Center for Mitochondrial and Epigenomic Medicine, Children's Hospital of Philadelphia, Philadelphia, Pennsylvania 19104, \\ USA, and The Department of Pathology and Laboratory Medicine, University of Pennsylvania, Philadelphia, Pennsylvania \\ 19104, USA
}

In the July 15, 2010, issue of Genes \& Development, Yoon and colleagues (pp. 1507-1518) report that, in a siRNA knockdown survey of 6363 genes in mouse C2C12 cells, they discovered 150 genes that regulated mitochondrial biogenesis and bioenergetics. Many of these genes have been studied previously for their importance in regulating transcription, protein and nucleic acid modification, and signal transduction. Some notable examples include Brac1, Brac2, Pax4, Sin3A, Fyn, Fes, Map2k7, Map3k2, calmodulin 3, Camk1, Ube3a, and Wnt. Yoon and colleagues go on to validate their observations by extensively documenting the role of Wnt signaling in the regulation of mitochondrial function.

The discovery that many "developmental" and "cancer" genes modify mitochondrial function will undoubtedly come as a surprise to some readers of Genes \& Development. Development is traditionally considered an anatomical issue involving the ordered proliferation and differentiation of cells to generate tissues and organs, programmed by the differential expression of nuclear DNA (nDNA)encoded genes. What does the mitochondrion have to do with this?

Development requires cell growth and reproduction, both of which are limited by the availability of energy. Thus, caloric energy is an important factor in the cellular environment that can influence cellular gene expression, DNA replication, growth, proliferation, differentiation, and even programmed death.

Usable energy is generated from dietary calories primarily via the mitochondrion. Therefore, mitochondrial energy production is essential for all cellular processes, and regulation of gene expression for growth and differentiation must be coordinated with regulation of mitochondrial bioenergetics.

Mitochondria generate energy by the oxidation of the electrons from hydrogen-reducing equivalents-by a reaction with oxygen. The reducing equivalents are ob-

[Keywords: RNAi screen; mitochondria; Wnt signaling; IRS-1]

${ }^{1}$ Correspondence.

E-MAIL dwallace@uci.edu; FAX (949) 824-6388.

Article is online at http://www.genesdev.org/cgi/doi/10.1101/gad.1960210. tained from dietary carbohydrates and fatty acids. The degradation of carbohydrates proceeds through glycolysis to pyruvate. Pyruvate then enters the mitochondrion via pyruvate dehydrogenase to generate $\mathrm{NADH}+\mathrm{H}^{+}$and acetyl-coenzyme A (acetyl-CoA). Acetyl-CoA proceeds to the tricarboxylic acid (TCA) cycle, which strips the hydrogens from the resulting hydrocarbons and transfers them to the electron carriers $\mathrm{NAD}^{+}$and FAD. Fatty acids are degraded in the mitochondrion by $\beta$-oxidation, a process that generates $\mathrm{NADH}+\mathrm{H}^{+}$, acetyl-CoA, and reduced electron transfer flavoprotein (ETF). The electrons from reduced ETF are transferred to coenzyme Q (CoQ) via the ETF dehydrogenase. CoQ is an electron carrier within the mitochondrial inner membrane that accepts two electrons from $\mathrm{NADH}+\mathrm{H}^{+}$via $\mathrm{NADH}$ dehydrogenase (respiratory complex I) or reduced flavoprotein dehydrogenases such as ETF dehydrogenase or succinate dehydrogenase (complex II) and passes them on to the $b_{1}$ complex (complex III). From complex III, the electrons are transferred to cytochrome $\mathrm{c}$, then to cytochrome $\mathrm{c}$ oxidase (complex IV), and finally to oxygen to generate water. The energy released as the electrons traverse complexes I, III, and IV is used to pump positive charges-protons-out of the mitochondrion to generate an electrochemical gradient across the mitochondrial inner membrane. The inner membrane gradient is positive and acidic on the outside, and negative and alkaline on the inside. The resulting electrical field is enormous, involving a membrane potential of about $-180 \mathrm{mV}$ separated by the thickness of the mitochondrial inner membrane. This capacitance within the $\sim 10^{17}$ mitochondria in the human body powers our lives.

One use of this mitochondrial potential energy is to generate ATP via the mitochondrial ATP synthase (complex V). Protons traverse an inner membrane proton channel within this rotary machine to drive the condensation of ADP and phosphate (Pi) to ATP.

From this simple summary of mitochondrial bioenergetics, it is immediately clear that fluctuations in the availability of calories for the cell must result in fluctuations in the intracellular concentrations of the mitochondrially generated intermediates acetyl-CoA and ATP. Electron flow through the mitochondrion also modulates the redox status of small molecules such as 
$\mathrm{NAD}(\mathrm{P})^{+} / \mathrm{NAD}(\mathrm{P}) \mathrm{H}+\mathrm{H}^{+}$, glutathione, and other thiol/ disulfide couples, and of the thiol/disulfide status, and thus the activity of many enzymes and transcription factors (Hansen et al. 2006; Kemp et al. 2008; Wallace et al. 2010).

ATP is the coreactant in virtually every signal transduction pathway, as well as histone phosphorylation. Acetyl-CoA is the coreactant for the acetylation of histones as well as many other proteins. With phosphorylation or acetylation, histone tails are converted from positively charged to negatively charged, resulting in their repulsion from the DNA sugar-phosphate backbone. This opens the chromatin, permitting transcription and replication. Thus, to a first-order approximation, when calories are abundant, chromatin is phosphorylated, acetylated, and decondensed; genes are expressed; and the cell grows and proliferates. When calories are scarce, the chromatin becomes dephosphorylated and deacetylated and condenses; gene expression subsides; and the cell ceases growth until calories again become prevalent (Wallace and Fan 2010).

Similarly, the redox status of $\mathrm{NAD}^{+} / \mathrm{NADH}+\mathrm{H}^{+}$regulates the deacetylation activity of Sirt1, and the redox status of $\mathrm{NADPH}^{+} / \mathrm{NADPH}+\mathrm{H}^{+}$regulates the redox state of glutathione and the antioxidant defenses. The $\mathrm{NADPH}+\mathrm{NADPH}+\mathrm{H}^{+}$ratio also regulates the redox status of thioredoxins 1 and 2, and of apurinic/apyrimidinic endonuclease/redox factor-1 (APE/Ref1 $1^{\text {red/ox }}$ ). The thioredoxin and APE/Ref1 ${ }^{\text {red/ox }}$ proteins in turn regulate the thiol/disulfide status and the activity of a wide variety of proteins, including many of the central transcription factors for growth, differentiation, antioxidant defenses, and inflammation. Hence, there is a direct link between the availability of calories in the environment and the decision to grow and reproduce, as mediated by the flux of reducing equivalents through the mitochondrion (Wallace 2009; Wallace and Fan 2010; Wallace et al. 2010).

While the genes for determining the structure of the cell and the spatial and temporal programs for defining tissue and organ development are encoded by the Mendelianinherited nDNA, which is encased in chromatin, the key components for the mitochondrial energy circuitry are encoded by the maternally inherited mitochondrial DNA (mtDNA). The mtDNA encodes 13 polypeptides plus the small and large ribosomal RNAs and the 22 transfer RNAs necessary for the bacterial-like mitochondrial protein synthesis system. All $13 \mathrm{mtDNA}$ protein genes are crucial for the mitochondrial energy production processoxidative phosphorylation-since these 13 proteins are the central electron and proton wires for energy production by complexes I, III, IV, and V (Wallace 2007; Efremov et al. 2010). All four of these complexes share the same mitochondrial inner membrane electrochemical gradient or capacitor (Wallace 2007). Therefore, like any integrated electrical circuit, all of the electrical characteristics of these complexes must be balanced to obtain optimal efficiency, and to avoid one complex becoming leaky and shorting the entire energy production system.

Because of the interdependence of complexes I, III, IV, and $\mathrm{V}$, their electronic components must coevolve to maintain the integrated circuit. This is achieved by placing the key electrical wiring elements on the same piece of nonrecombining DNA: the mtDNA. Therefore, each new mtDNA mutation that arises occurs on a preexisting background of functional variants, and the entire system is acted on by natural selection as a unit. Uniparental inheritance then blocks the mixing of mtDNAs from different maternal lineages, and thus the exchange of circuit components from mtDNAs that are optimized for different energetic environments. Consequently, mtDNA lineages can only evolve by the sequential accumulation of functional variants along radiating maternal lineages, with each branch of the tree becoming optimized to cope with differences in the energetic characteristics of the various regions of the species' niche.

In addition to the mtDNA genes, the mitochondrial genome encompasses hundreds if not thousands of nDNA genes. The nDNA-encoded bioenergetic genes determine the mitochondrion's structure, replication, biogenesis, fission and fusion equilibriums, mitophagy turnover rate, intracellular quantity, etc. These genes are scattered across the chromosomes, yet need to be coordinately regulated to permit optimal energy production.

Unlike mtDNA genes, the anatomical and developmental genes found in the nDNA can benefit from recombination. Reassortment of anatomical genes can lead to new structures. These modified structures may then permit the exploitation of alternative reservoirs of calories within the biosphere, resulting in speciation.

The mutation rate of the mtDNA is very high, while that of the nDNA is very low. The high mutation rate of the mtDNA, with its vital genes, is potentially quite hazardous, since it could result in a high genetic load of deleterious mutations that could erode the vitality of the species. This problem is ameliorated by the existence of an intraovarian selection system that eliminates the most deleterious mtDNA mutations before ovulation. Hence, only the milder and potentially adaptive mutations are introduced into the population (Fan et al. 2008; Stewart et al. 2008). This prefertilization selection is possible for the mitochondrial genes because energy production is manifest at the single-cell level, thereby permitting phenotypic selection to act on the individual oocyte. In contrast, anatomical structures can be manifest only after development results in complex tissues and organs, and hence selection must act on anatomical genes post-fertilization. As a result, the nDNA mutation rate must remain low to avoid excessive nDNA genetic load (Wallace 2010).

The high mtDNA mutation rate and its direct effect on bioenergetics make the mtDNA an excellent genetic system for the adaptation of species subpopulations to regional differences in their energetic environment. These heritable adaptive changes in the mtDNA are augmented by reversible epigenetic changes in the regulation of the nDNA-encoded bioenergetic genes. Epigenetic changes in the regulation of bioenergetic genes permit response to cyclic daily and seasonal changes in the local energy environment. Therefore, the primary systems for animal species to adapt to their bioenergetic 
environment are genetic alterations in the mtDNA energy genes and reversible epigenomic changes in the regulation of the nDNA-encoded bioenergetic genes (Wallace 2010; Wallace and Fan 2010).

The realization that energetics is a highly important environmental factor for the survival of individuals within a species shifts the emphasis in the search for important clinical variation in Homo sapiens from the nDNA, which regulates anatomy, to the mtDNA and the epigenome, which regulate bioenergetics. Alterations in the mtDNA would then be predicted to provide the heritable common variants that predispose to disease. Changes in the epigenome, which encompasses all alterations of the genome and associated signal transduction pathways except DNA mutations, modulate the inherited mtDNA effects through the regulation of nDNA-encoded bioenergetic gene expression. The status of the epigenome is modulated by the availability of high-energy intermediates (ATP and acetyl-CoA) that reflect the energy flux through the cellular mitochondria, and thus provide the environmental cues. Hence, mtDNA genetic changes and epigenome fluctuations may be the primary arbiters of human metabolism and, consequently, the critical factors in individual predisposition to metabolic and degenerative diseases (Wallace 2005, 2008; Wallace et al. 2007).

Since a key issue for environmental adaptation is bioenergetics, it follows that transcriptional networks important in cellular growth and differentiation must also regulate bioenergetics. Hence, the observations of Yoon et al. (2010) that nDNA regulatory pathways affect mitochondrial function may be the harbingers for the identification of an ever increasing number of associations between bioenergetics, gene regulation, developmental biology, and the predisposition to disease.

\section{Acknowledgments}

This work was supported by NIH grants R01 NS211328, AG24373, DK73691, AG16573, and NS41850; CIRM Comprehensive Grant RC1-00353-1; and a Doris Duke Clinical Interfaces Grant.

\section{References}

Efremov RG, Baradaran R, Sazanov LA. 2010. The architecture of respiratory complex I. Nature 465: 441-445.

Fan W, Waymire K, Narula N, Li P, Rocher C, Coskun PE, Vannan MA, Narula J, MacGregor GR, Wallace DC. 2008. A mouse model of mitochondrial disease reveals germline selection against severe mtDNA mutations. Science 319: 958-962.

Hansen JM, Go YM, Jones DP. 2006. Nuclear and mitochondrial compartmentation of oxidative stress and redox signaling. Annu Rev Pharmacol Toxicol 46: 215-234.

Kemp M, Go YM, Jones DP. 2008. Nonequilibrium thermodynamics of thiol/disulfide redox systems: A perspective on redox systems biology. Free Radic Biol Med 44: 921937.

Stewart JB, Freyer C, Elson JL, Wredenberg A, Cansu Z, Trifunovic A, Larsson NG. 2008. Strong purifying selection in transmission of mammalian mitochondrial DNA. PLOS Biol 6: e10. doi: 10.1371/journal.pbio.0060010.
Wallace DC. 2005. A mitochondrial paradigm of metabolic and degenerative diseases, aging, and cancer: A dawn for evolutionary medicine. Annu Rev Genet 39: 359-407.

Wallace DC. 2007. Why do we have a maternally inherited mitochondrial DNA? Insights from evolutionary medicine. Annu Rev Biochem 76: 781-821.

Wallace DC. 2008. Mitochondria as chi. Genetics 179: 727-735.

Wallace DC. 2009. Mitochondria, bioenergetics, and the epigenome in eukaryotic and human evolution. Cold Spring Harb Symp Quant Biol 74: 383-393.

Wallace DC. 2010. Colloquium paper: Bioenergetics, the origins of complexity, and the ascent of man. Proc Natl Acad Sci 107: 8947-8953.

Wallace DC, Fan W. 2010. Energetics, epigenetics, mitochondrial genetics. Mitochondrion 10: 12-31.

Wallace DC, Lott MT, Procaccio V. 2007. Mitochondrial genes in degenerative diseases, cancer and aging. In Emery and Rimoin's principles and practice of medical genetics, 5th Ed. (ed. DL Rimoin, et al.), pp. 194-298. Churchill Livingstone Elsevier, Philadelphia.

Wallace DC, Fan W, Procaccio V. 2010. Mitochondrial energetics and therapeutics. Annu Rev Pathol 5: 297-348.

Yoon JC, Ng A, Kim BH, Bianco A, Xavier RJ, Elledge SJ. 2010. Wnt signaling regulates mitochondrial physiology and insulin sensitivity. Genes Dev 24: 1507-1518. 


\section{Erratum}

Genes \& Development 24: 1571-1573 (2010)

The epigenome and the mitochondrion: bioenergetics and the environment Douglas C. Wallace

In the above-mentioned paper, the word "environment" was misspelled in the title. This has been corrected in the online version.

We apologize for the error. 


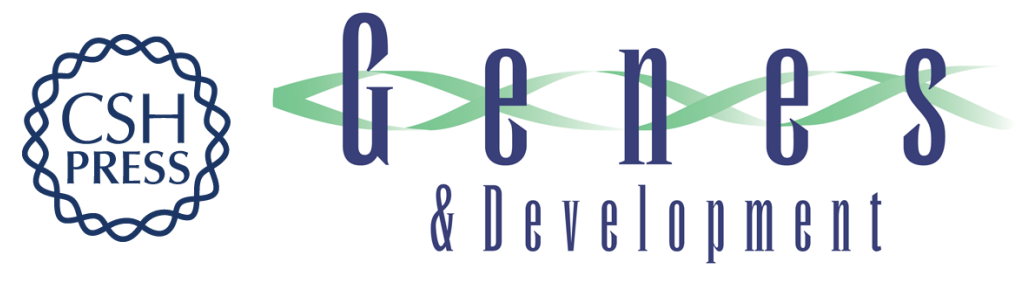

\section{The epigenome and the mitochondrion: bioenergetics and the environment}

Douglas C. Wallace

Genes Dev. 2010, 24:

Access the most recent version at doi:10.1101/gad.1960210
Related Content Erratum: The epigenome and the mitochondrion: bioenergetics and the environment
Douglas C. Wallace
Genes Dev. September , 2010 24: 1961

References This article cites 13 articles, 4 of which can be accessed free at:

http://genesdev.cshlp.org/content/24/15/1571.full.html\#ref-list-1

Articles cited in:

http://genesdev.cshlp.org/content/24/15/1571.full.html\#related-urls

\section{License}

Email Alerting

Service

Receive free email alerts when new articles cite this article - sign up in the box at the top right corner of the article or click here.

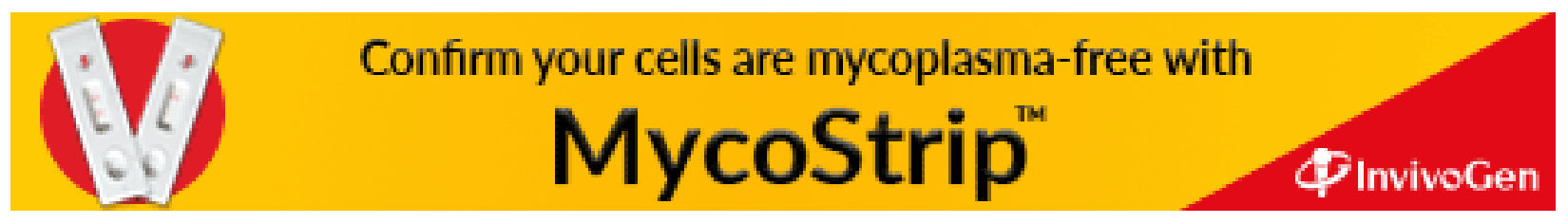

